\title{
FLUTUAÇÃO POPULACIONAL E INTENSIDADE DE INFESTAÇÃ̃O DA BROCA-DOS-FRUTOS EM CUPUAÇU
}

\author{
Marcílio José Thomazini* \\ Embrapa Acre, Rod. BR 364, km 14 - C.P. 321 - CEP: 69908-970 - Rio Branco, AC. \\ ${ }^{*}$ Autor correspondente <marcilio@cpafac.embrapa.br>
}

RESUMO: Dentre as pragas do cupuaçueiro Theobroma grandiflorum (Wild. ex Spreng.) Schum., a brocados-frutos, Conotrachelus humeropictus Fiedler (Coleoptera: Curculionidae), é a mais importante, devido aos danos causados e por estar disseminada em alguns Estados da região Norte do Brasil. Os objetivos deste trabalho foram avaliar a flutuação populacional de adultos de $C$. humeropictus, determinar a intensidade de infestação e caracterizar o ataque de larvas desta praga em frutos de cupuaçueiros, em sistemas agroflorestais no Estado de Rondônia. Para obter a flutuação populacional de adultos da broca, foram amostradas semanalmente, durante o período de março/98 a julho/00, 20 plantas de cupuaçu, pelo método do sacolejo, em duas áreas de agrossilvicultores. A avaliação da população de larvas foi realizada durante duas safras, onde foram coletados e abertos frutos atacados pela broca. A determinação da infestação da praga foi obtida através da porcentagem de frutos broqueados. Adultos de $C$. humeropictus ocorrem durante todo ano nas plantas de cupuaçu, na área estudada, mas predominam na floração, início da frutificação e durante o período de safra. Tanto os frutos verdes como os maduros são atacados, sendo que larvas de idades diferentes podem ocorrem em um mesmo fruto. Perdas superiores a $50 \%$ na produção de frutos, devido ao ataque da broca, ressaltam a importância desta praga na região.

Palavras-chave: Conotrachelus humeropictus, Theobroma grandiflorum, Amazônia Ocidental, sistemas agroflorestais, inseto-praga

\section{POPULATION FLUCTUATION AND INFESTATION LEVELS OF THE CUPUAÇU FRUIT BORER}

\begin{abstract}
The most important pest of the cupuaçu crop is the fruit borer, Conotrachelus humeropictus Fiedler (Coleoptera: Curculionidae), wich severely damages fruits and is disseminated all over North Brazil. The objectives of this study were evaluating the population fluctuations of $C$. humeropictus adults, infestation levels and to characterize the pest larval attack in cupuaçu fruits of agroforestry systems of the Rondonia State, Brazil. Population fluctuations from C. humeropictus adults were evaluated weekly from March/98 to July/00 in twenty cupuaçu plants, by shaking the tree branches, of two producer areas. During two harvest periods, fruits attacked by the borer were collected and examined for evaluation of larvae population. Pest infestation was determined by the percentage of damaged fruits. C. humeropictus adults occur year around on cupuaçu plants, but predominate at the stages of flowering, fruit formation and during the harvest period. It was observed that mature and non-mature fruits are attacked by the pest; larvae of different ages can occur in a same fruit; the insect may cause losses greater than $50 \%$ of fruit yield.

Key words: Conotrachelus humeropictus, Theobroma grandiflorum, Western Amazonia, agroforestry systems, insect-pest
\end{abstract}

\section{INTRODUÇÃO}

Nos sistemas agroflorestais da região Norte, o cupuaçueiro é uma das mais importantes frutíferas exploradas comercialmente. Isto deve-se ao grande potencial existente no aproveitamento da polpa, das sementes e, também, devido à conquista de mercado em outras regiões do País e no exterior.

Apesar da população de insetos presentes na cultura do cupuaçueiro ser numerosa, poucas espécies são consideradas como pragas, causando dano econômico, existindo também espécies benéficas como predadores e polinizadores (Pamplona et al., 1992; Ribeiro, 1997; Silva et al., 1997; Teixeira \& Veld, 1997; Venturieri et al., 1997).
Dentre as pragas citadas em cupuaçueiro, a broca-dos-frutos, inseto pertencente ao gênero Conotrachelus (Coleoptera, Curculionidae), é a mais importante atualmente, devido aos danos causados pelas larvas, que se alimentam das sementes e constroem galerias no interior dos frutos, e por estar disseminada em alguns Estados da região Norte, principalmente em Rondônia e Amazonas, sendo que no Pará e no Acre o inseto não é tão freqüente (Garcia et al., 1997). Bondar (1937) citou que dentro do gênero Conotrachelus haveria mais de 500 espécies, todas no Continente Americano, sendo 73 delas no Brasil. A maioria das espécies desenvolvem-se em frutos de árvores silvestres.

Conotrachelus humeropictus Fiedler foi relatado como a espécie que ataca o cupuaçueiro na região Norte 
(Trevisan \& Mendes, 1991; Venturieri, 1993); no entanto, Aguilar (1999), com base em dados biológicos e comportamentais em laboratório, levantou a hipótese que pudesse ocorrer outra espécie na região de Manaus, no Estado do Amazonas.

C. humeropictus foi registrado pela primeira vez em 1981, atacando frutos de cacau, Theobroma cacao L., em Rondônia, mais especificamente no município de Cacoal (Mendes et al., 1982), sendo considerado uma das pragas mais importantes dessa cultura (Trevisan, 1989). Foi constatado que essa espécie ataca ainda a jaboticabeira (Eugenia cauliflora D.C.) (Silva et al., 1968), ocorrendo também, segundo Almeida \& Almeida (1987), em plantas silvestres como o cacauí ( $T$. speciosum Spreng.) e cacaurana (T. microcarpum Bern.).

Esta praga é de difícil controle, visto que o ovo e a larva ficam alojados no interior do fruto. A larva, por sua vez, sai do fruto para empupar no solo, numa profundidade de 5 a $10 \mathrm{~cm}$, de onde emerge o adulto. Esses adultos podem se alimentar, na natureza, em folhas e frutos novos de cacau, sendo observados também se alimentando em bananeiras (Musa sp.) e jaqueiras (Artocarpus integrifolia L.). A fase larval dura, em média, 26,6 dias, em condições de $27^{\circ} \mathrm{C}, 80 \%$ U.R. e $12 \mathrm{~h}$ de fotofase (Mendes et al., 1997). Os frutos infestados, quando atacados muito novos, caem antes do amadurecimento. Aqueles que atingem 0 amadurecimento têm a polpa totalmente destruída devido à entrada de microrganismos (Garcia et al., 1997).

Nos sistemas agroflorestais do Projeto Reca (Reflorestamento Econômico Consorciado e Adensado), no distrito de Nova Califórnia, Porto Velho-RO, o ataque de $C$. humeropictus não é uniforme; contudo, perdas superiores a $50 \%$ na produção de cupuaçu são verificadas em muitas propriedades (Oliveira, 1997).

Um levantamento detalhado e sistemático sobre essas perdas não foi realizado, para saber se a incidência de ataque e a ocorrência de larvas podem variar com o desenvolvimento dos frutos. Também se faz necessário determinar a variação populacional do inseto em função dos fatores bióticos (alimento, inimigos naturais, vegetação ao redor dos plantios) e abióticos (precipitação pluviométrica e temperatura), visando determinar se o adulto ocorre na cultura do cupuaçu mesmo sem a presença de frutos, se a mata ao redor da cultura pode influenciar na intensidade de ataque da praga e se as condições climáticas como chuva e temperatura afetam a população do inseto. Tais informações devem ser usadas para subsidiar possíveis intervenções de monitoramento e controle.

Os objetivos deste trabalho foram avaliar a flutuação populacional de adultos de $C$. humeropictus, determinar a intensidade de infestação e caracterizar - ataque de larvas desta praga em frutos de cupuaçueiros, em sistemas agroflorestais no Estado de Rondônia.

\section{MATERIAL E MÉTODOS}

Os levantamentos foram conduzidos de março de 1998 a julho de 2000, em duas áreas de agrossilvicultores associados ao Projeto Reca, localizado na BR 364, Km 142, distrito de Nova Califórnia, Porto Velho, RO entre as coordenadas S $02^{\circ} 54^{\prime} 45^{\prime \prime}$ e $3^{\circ} 16^{\prime}$ $36^{\prime \prime}$ e W $47^{\circ} 55^{\prime} 38^{\prime \prime}$ e $48^{\circ} 26^{\prime} 44^{\prime \prime}$. Essas áreas eram compostas de sistemas agroflorestais com, aproximadamente, 2 ha e cerca de 10 anos de idade, compostos de cupuaçu, pupunha (Bactris gasipaes Kunth) e castanha-do-brasil (Bertholletia excelsa H.B.K.).

Para se obter a flutuação populacional de adultos, foram avaliadas, semanalmente, 20 plantas de cupuaçu em duas áreas de produtores (área 1 e área 2 ). Tais plantas foram sempre as mesmas a serem amostradas durante todo o período de estudo, estando distantes, em média, $10 \mathrm{~m}$ umas das outras. Em uma das áreas (área 2), dez plantas, dentre as 20, foram escolhidas próximas à mata ( 5 a $15 \mathrm{~m}$ de distância), para verificar uma possível influência da mesma na intensidade e no início do ataque. A mata em questão constitui-se de fragmento de floresta tropical primária, cujas espécies de valor comercial foram retiradas.

Os insetos foram amostrados pelo método do sacolejo, que consiste em estender-se uma tela de nylon com $4 \mathrm{~m}$ de cada lado, sob a copa das plantas de cupuaçu e em seguida, sacudir todos os ramos com projeção sob a tela por cerca de $5 \mathrm{~s}$ (Trevisan, 1989). Os adultos de Conotrachelus caídos na tela foram rapidamente contados e liberados.

A porcentagem média de frutos atacados pela broca (frutos caídos no chão e com orifício de saída do inseto) foi determinada semanalmente nas mesmas áreas e sob a copa das mesmas plantas utilizadas na flutuação populacional dos adultos, bem como diariamente, na safra de 1998, na agroindústria de beneficiamento da polpa do cupuaçu, localizada na sede do Projeto Reca, quando da chegada dos frutos para pesagem.

Durante as safras de 1999 (fevereiro a maio) e 2000 (janeiro a abril), na área 1, três vezes por mês foram coletados de 30 a 60 frutos atacados pela broca (caídos no chão e com, pelo menos, um orifício de saída do inseto). Esses frutos foram separados em verdes e maduros, sendo então abertos, registrando-se o número e o tamanho das larvas presentes. Estimou-se também o número total de larvas por fruto, através da contagem dos orifícios de saída das mesmas. Cada orifício significa uma larva madura que deixou o fruto para empupar no solo.

Larvas de último ínstar foram colocadas em recipientes de vidro, contendo solo peneirado e esterilizado e mantido permanentemente umedecido, para permitir o empupamento das mesmas e assim obter exemplares adultos da broca e/ou a emergência de eventuais parasitóides. Tais exemplares obtidos foram enviados para especialistas, para identificação. Alguns exemplares adultos, amostrados pelo método do 
sacolejo, também foram enviados para identificação. Isso foi realizado para confirmar se os insetos que estavam na copa das árvores pertenciam à mesma espécie daqueles que atacavam os frutos.

Foram realizadas correlações simples (teste de correlações de Pearson) entre o número mensal total de adultos de $C$. humeropictus e os dados mensais de temperatura média $\left({ }^{\circ} \mathrm{C}\right)$ e precipitação pluviométrica total (mm) coletados no local de estudo, durante o período dos levantamentos.

\section{RESULTADOS E DISCUSSÃO}

Adultos de C. humeropictus foram coletados em todos os meses amostrados, principalmente na época da floração e formação de frutos (novembro/dezembro) e durante a safra (janeiro/maio) (Figuras 1 e 2). Nos outros meses (junho/outubro), a coleta de adultos nas plantas de cupuaçu ocorreu em menor intensidade, o que pode estar relacionado à utilização destas plantas como abrigo, à presença de estruturas reprodutivas produzidas fora de época, ou à alimentação dos adultos em partes vegetativas da planta, como o observado em cacau por Mendes et al. (1997).

Não houve correlação significativa, verificado através do teste de correlações de Pearson, entre a flutuação populacional de adultos da broca das duas áreas amostradas com a precipitação pluviométrica e temperatura mensais do período de avaliação, apesar da época de baixas precipitações (junho a setembro) (Figura 3) ser uma época de menor número de adultos coletados (Figuras 1 e 2).

Nas lavouras cacaueiras de Rondônia, Trevisan (1989) e Mendes \& Trevisan (1991) verificaram que C. humeropictus ocorre, independentemente de sua fase de desenvolvimento, em todos os meses do ano, sendo que as maiores populações de adultos são observadas nos períodos de junho/julho, setembro/outubro e dezembro, enquanto que as maiores infestações de larvas estão diretamente relacionadas aos picos de frutificação.

A distribuição da praga não é homogênea na região do Projeto Reca, existindo propriedades com intenso ataque de broca, outras com infestações menores e outras ainda sem a presença do inseto. Isso pode ser notado pelo total de adultos da broca coletados nas duas áreas amostradas (Figuras 1 e 2), que ficam distantes cerca de $3 \mathrm{Km}$ uma da outra. Possivelmente, muitos fatores podem determinar essas diferenças, como a dispersão da praga, tratos culturais, idade das plantas, densidade de plantas de cupuaçu nos sistemas agroflorestais, entre outros.

As plantas amostradas próximas à mata, na área 2 , apresentaram um número de adultos maior que aquelas amostradas no interior da referida área (Figura 2). Essa diferença populacional (com mata e sem mata), dentro da área 2, não significou, em geral, um aumento na porcentagem de frutos broqueados pois, nas amostragens de março e abril de 1998, a porcentagem de frutos atacados nas plantas com mata ao redor, foi superior ao valor encontrado nas plantas cultivadas sem mata próxima. Entretanto, no ano de 2000, quando foram amostrados todos os meses de safra, não houve diferença na infestação (Tabela 1).

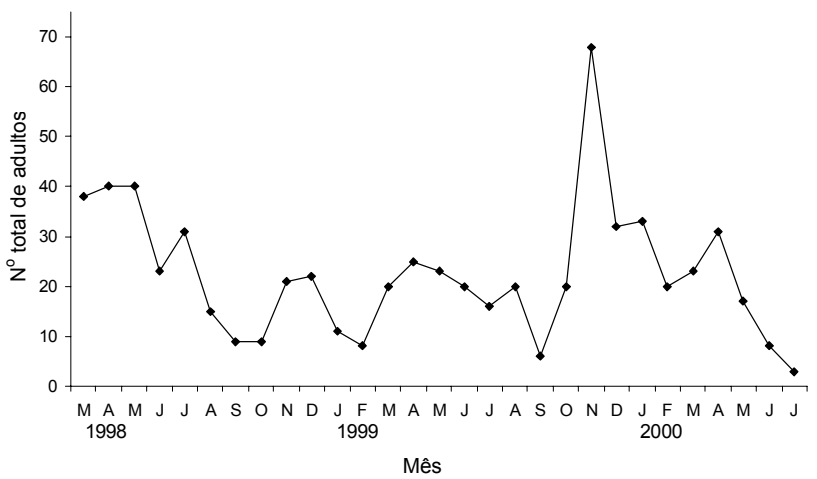

Figura 1 - Flutuação populacional de adultos de Conotrachelus humeropictus no período de março/98 a julho/00, amostradas pelo método do sacolejo, em 20 cupuaçueiros componentes de um sistema agroflorestal sem mata ao redor (área 1). Nova Califórnia, RO.

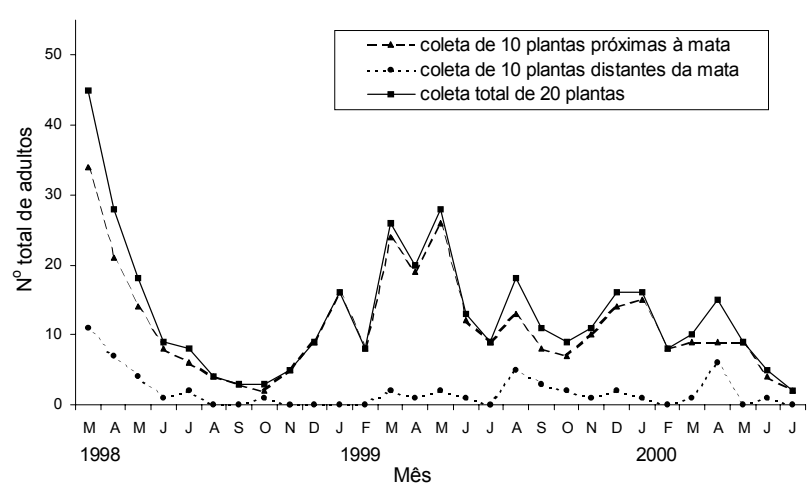

Figura 2 - Flutuação populacional de adultos de Conotrachelus humeropictus no período de março/98 a julho/00, amostrados pelo método do sacolejo, em 20 cupuaçueiros componentes de um sistema agroflorestal com mata adjacente (área 2). Nova Califórnia, RO.

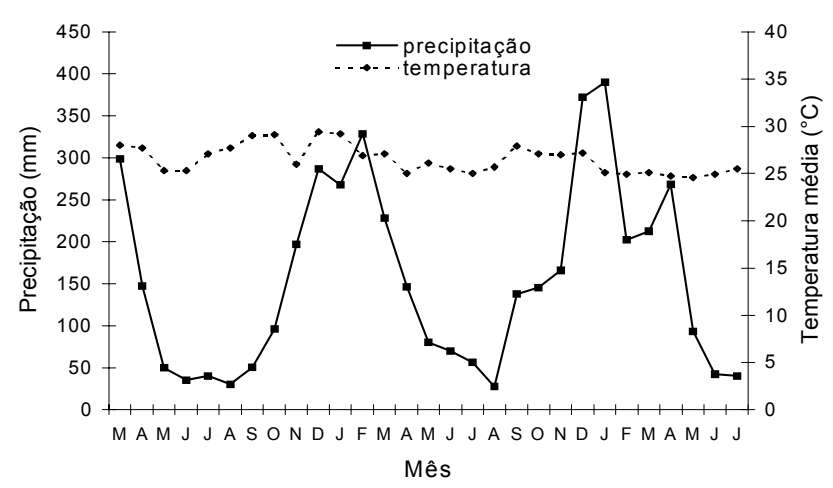

Figura 3 - Temperatura média e precipitação pluviométrica, no período de março de 1998 a julho de 2000, da região do Projeto Reca, RO, Brasil. 
O real papel da mata na população da broca deve ser melhor elucidado, para verificar se a mesma pode servir como fonte de hospedeiros alternativos e/ou abrigo para essa praga, e se isso pode influir positiva ou negativamente na população do inseto dentro da lavoura. Em cacau C. humeropictus predomina no interior da cultura e não nas bordaduras próximas à mata, indicando, que tanto os insetos que migram da mata para a lavoura quanto os emergem na lavoura, encontram condições favoráveis para a sua permanência e não mais retornam à mata (Trevisan, 1989). Assim, as características das culturas podem influenciar também nessa questão pois frutos de cacau estão disponíveis, em menor ou maior intensidade, durante todo o ano, o que não ocorre com o cupuaçu.

Apesar dos dados de intensidade de infestação das safras de 1998 e 1999 não terem sido coletados em todos os meses, verificou-se, principalmente no sistema agroflorestal não circundado por mata, que a percentagem média de frutos atacados aumentou de 1998 para 2000. Nesse último ano, em média, $70,4 \%$ dos frutos coletados estavam atacados pela praga (Tabela 1). Esse fato pode ser explicado pela alta população de adultos já no início da formação dos frutos, no final do ano de 1999 (Figura 1). Em março de 1998, a porcentagem de frutos atacados pela broca foi de $15,5 \%$, enquanto que no mesmo mês, em 2000 , esse valor chegou a $75 \%$. Em fevereiro de 1999 , $58,1 \%$ dos frutos estavam atacados, contra $86,6 \% \mathrm{em}$ fevereiro de 2000 (Tabela 1). Essa situação também foi constatada na área 2, onde em março de 1998 a porcentagem total de frutos atacados foi de $24,2 \%$, contra $59,1 \%$ em março de 2000 . Nas plantas próximas à mata, em janeiro de $1999,51,2 \%$ dos frutos estavam broqueados, contra 90,9\% em janeiro de 2000 (Tabela 1).
A porcentagem de frutos atacados diminui do início para o fim da safra (Tabela 1), ao contrário da população de adultos da broca, que em geral, aumenta nesse período (Figuras 1 e 2). Em cacau o ataque da broca foi maior nos meses de maior frutificação, ou seja, com maior porcentagem de frutos disponíveis (Trevisan, 1989). Possivelmente, a maior disponibilidade de frutos de cupuaçu possa também determinar um maior índice de ataque.

Laker \& Trevisan (1992) e Oliveira (1997) encontraram perdas na safra de cupuaçu de até $50 \%$ e acima de $50 \%$, respectivamente, causadas pela broca-dos-frutos em Rondônia. Em algumas áreas infestadas no Estado do Amazonas, a queda na produção de cupuaçu atingiu $20 \%$ no primeiro ano, $60 \%$ no segundo, chegando até a $100 \%$ no terceiro ano, com muitos produtores abandonando a cultura (Garcia et al., 1997). Em Manaus, a intensidade média de infestação mensal variou de 85,0 a $93,3 \%$ na safra $97 / 98$ (Aguilar, 1999).

Com relação aos frutos coletados e levados à indústria, ao final da safra 97/98, a média semanal de frutos atacados foi de $5,3 \%$ (Tabela 2 ), sugerindo que grande parte dos produtores está separando os frutos atacados antes do envio para o beneficiamento, mas uma parte ainda chega à indústria infestada pela broca. Tal fato sugere que deva haver uma rigorosa classificação e verificação da presença de larvas no local de armazenamento dos frutos que chegam do campo, para a destruição das mesmas (Thomazini, 1998).

Para avaliar a relação entre ataque da broca e estádio de desenvolvimento dos frutos, foram realizadas 12 amostragens de fevereiro a maio de 1999 , sendo que

Tabela 1 - Número total de frutos, número de frutos broqueados e porcentagem média de frutos de cupuaçu atacados por Conotrachelus humeropictus em duas áreas com sistemas agroflorestais. Nova Califórnia, RO. Brasil.

\begin{tabular}{|c|c|c|c|c|c|c|c|c|c|c|c|c|}
\hline \multirow[b]{3}{*}{ Mês } & \multirow{2}{*}{\multicolumn{3}{|c|}{$\begin{array}{c}\text { Área } 1 \\
\text { Sem mata ao redor } \\
(20 \text { plantas })\end{array}$}} & \multicolumn{9}{|c|}{ Área 2} \\
\hline & & & & \multicolumn{3}{|c|}{$\begin{array}{c}\text { Com mata ao redor } \\
(10 \text { plantas })\end{array}$} & \multicolumn{3}{|c|}{$\begin{array}{l}\text { Sem mata ao redor } \\
(10 \text { plantas })\end{array}$} & \multicolumn{3}{|c|}{$\begin{array}{c}\text { Total } \\
(20 \text { plantas }) \\
\end{array}$} \\
\hline & Total & Broca & $\%$ & Total & Broca & $\%$ & Total & Broca & $\%$ & Total & Broca & $\%$ \\
\hline \multicolumn{13}{|c|}{ 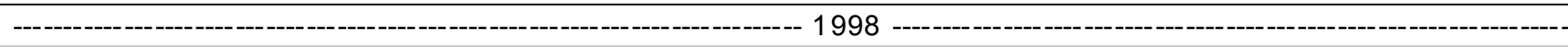 } \\
\hline Mar & 110 & 17 & 15,5 & 81 & 25 & 30,9 & 39 & 04 & 10,3 & 120 & 29 & 24,2 \\
\hline Abr & 30 & 04 & 13,3 & 23 & 04 & 18,2 & 24 & 02 & 8,3 & 46 & 06 & 13,0 \\
\hline Total & 140 & 21 & 15,0 & 103 & 29 & 28,2 & 63 & 06 & 9,5 & 166 & 35 & 21,1 \\
\hline \multicolumn{13}{|c|}{ 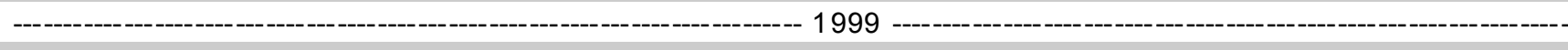 } \\
\hline Jan & 43 & 27 & 62,8 & 43 & 22 & 51,2 & ${ }^{1}$ & - & - & - & - & - \\
\hline Fev & 43 & 25 & 58,1 & 58 & 38 & 65,5 & - & - & - & - & - & - \\
\hline Total & 86 & 52 & 60,5 & 101 & 60 & 59,4 & - & - & - & - & - & - \\
\hline \multicolumn{13}{|c|}{ 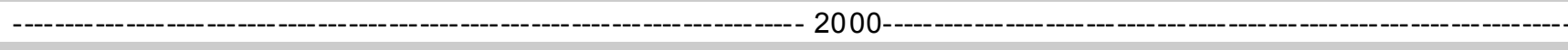 } \\
\hline Jan & 63 & 58 & 92,1 & 22 & 20 & 90,9 & 19 & 19 & 100,0 & 41 & 39 & 95,1 \\
\hline Fev & 209 & 181 & 86,6 & 77 & 55 & 71,4 & 46 & 36 & 78,3 & 123 & 91 & 74,0 \\
\hline Mar & 80 & 60 & 75,0 & 69 & 44 & 63,8 & 41 & 21 & 51,2 & 110 & 65 & 59,1 \\
\hline$A b r$ & 114 & 29 & 25,4 & 85 & 15 & 17,7 & 47 & 05 & 10,6 & 132 & 20 & 15,2 \\
\hline Total & 466 & 328 & 70,4 & 253 & 134 & 53,0 & 153 & 81 & 52,9 & 406 & 215 & 53,0 \\
\hline
\end{tabular}

${ }^{1}$ não houve produção significativa 
de um total de 549 frutos atacados registrados, 131 (24\%) estavam verdes e $418(76 \%)$ estavam maduros. Já nas 12 amostragens realizadas de janeiro a abril de $2000,152(32,3 \%)$ dos frutos estavam verdes e 319 $(68,7 \%)$ estavam maduros, do total de 471 frutos atacados registrados. No primeiro mês de avaliação de 1999 (fevereiro) a porcentagem de frutos verdes atacados correspondeu a quase $50 \%$ do total de frutos atacados. Em 2000, onde as avaliações começaram mais cedo, o número de frutos verdes infestados superou, em janeiro, os $50 \%$ do total de frutos atacados. A proporção de frutos maduros atacados foi crescendo, em relação aos verdes, até o final da safra, quando em maio de 1999 (Figura 4).

No início da safra, praticamente metade dos frutos atacados e caídos ao chão estavam verdes, com muitas larvas completando o ciclo (orifícios de saída). Esses frutos devem ser imediatamente destruídos visando à redução populacional da praga.

Nos frutos maduros atacados predominaram as larvas grandes ( $4^{\circ}$ ínstar) (Tabela 3 ). Com relação aos

Tabela 2 - Frutos de cupuaçu atacados por Conotrachelus humeropictus recebidos na indústria de beneficiamento do Projeto Reca. Nova Califórnia, RO. 1998.

\begin{tabular}{|c|c|c|c|}
\hline Mês & $\begin{array}{l}\text { Total de frutos } \\
\text { recebidos }\end{array}$ & $\begin{array}{c}\text { Total de frutos } \\
\text { atacados }\end{array}$ & $\begin{array}{l}\text { Frutos } \\
\text { atacados }\end{array}$ \\
\hline & \multicolumn{2}{|c|}{ 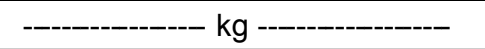 } & $\%$ \\
\hline $\mathrm{Fev}^{1}$ & 45950 & 2388 & 5,2 \\
\hline Mar & 126481 & 9745 & 7,7 \\
\hline Abr & 101583 & 4405 & 4,3 \\
\hline Mai & 40474 & 594 & 1,5 \\
\hline Jun & 9920 & 223 & 2,2 \\
\hline Total & 324408 & 17355 & 5,3 \\
\hline
\end{tabular}

'Somente da última quinzena. frutos verdes, ora predominaram as médias (em torno do $3^{\circ}$ instar), ora as grandes. O número total de larvas/fruto, tanto nos verdes quanto nos maduros diminuiu, de uma maneira geral, do início para o fim da safra. Foi verificado que larvas de diferentes idades podem ocorrer em um mesmo fruto, pois na maioria das coletas, larvas pequenas, médias e grandes estavam presentes (Tabela $3)$.

O número de larvas que abandonaram os frutos, medido pelo número de orifícios de saída, foi sempre superior ao dobro do número de larvas presentes, no ano de 2000 , mostrando que as larvas poderiam ter saído com o fruto ainda preso à planta ou durante o período entre a queda do fruto e a avaliação, que foi em média, de 3 a 6 dias. Já em 1999, quando a avaliação foi feita 2 a 4 dias após a coleta dos frutos, essa diferença não foi tão acentuada nos frutos maduros, sendo que nos frutos verdes o número médio de larvas presentes foi superior ao número de orifícios de saída (Tabela 3). Este fato tem uma importante implicação prática, denotando a necessidade de se coletar os frutos caídos no chão o

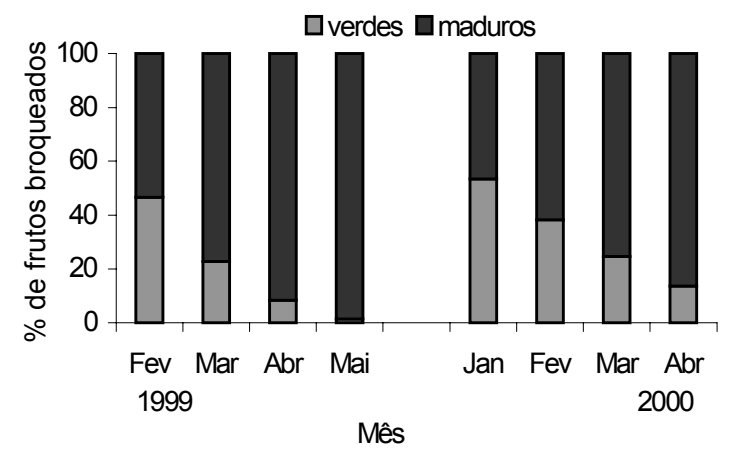

Figura 4 - Relação entre frutos verdes e maduros de cupuaçueiro atacados pela broca dos frutos, Conotrachelus humeropictus, em um sistema agroflorestal. Nova Califórnia, Porto Velho, RO.

Tabela 3 - Número médio de larvas de diferentes tamanhos de Conotrachelus humeropictus e de orifícios de saída de larvas por fruto de cupuaçu, em diferentes estágios de maturação, em um sistema agroflorestal. Nova Califórnia, Porto Velho, RO.

\begin{tabular}{|c|c|c|c|c|c|c|c|c|c|c|c|c|}
\hline \multirow[b]{3}{*}{ Mês } & \multicolumn{6}{|c|}{ Fruto verde broqueado } & \multicolumn{6}{|c|}{ Fruto maduro broqueado } \\
\hline & \multirow{2}{*}{$\begin{array}{l}\mathrm{N}^{\circ} \text { de frutos } \\
\text { avaliados }\end{array}$} & \multicolumn{3}{|c|}{ Número de larvas/fruto } & \multirow{2}{*}{$\begin{array}{c}\mathrm{N}^{\circ} \mathrm{de} \\
\text { Orifícios }{ }^{4}\end{array}$} & \multirow[b]{2}{*}{ Total $^{5}$} & \multirow{2}{*}{$\begin{array}{l}\mathrm{N}^{\circ} \text { de frutos } \\
\text { avaliados }\end{array}$} & \multicolumn{3}{|c|}{ Número de larvas/fruto } & \multirow{2}{*}{$\begin{array}{c}\mathrm{N}^{\circ} \mathrm{de} \\
\text { Orifícios }\end{array}$} & \multirow[b]{2}{*}{ Total ${ }^{5}$} \\
\hline & & Pequena $^{1}$ & Média $^{2}$ & Grand e $^{3}$ & & & & Pequena $^{1}$ & Média $^{2}$ & Grande $^{3}$ & & \\
\hline & & 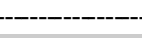 & 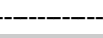 & 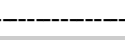 & -- & - & . & ---- & --- & ---- & ------- & ------ \\
\hline Fev & 84 & 0,6 & 0,4 & 1,1 & 2,0 & $4,1 \pm 0,41$ & 96 & 0,2 & 0,3 & 1,1 & 2,8 & $4,4 \pm 0,12$ \\
\hline Mar & 33 & 0,3 & 0,8 & 0,6 & 1,0 & $2,7 \pm 0,28$ & 112 & 0 & 0,1 & 0,5 & 2,1 & $2,7 \pm 0,56$ \\
\hline Abr & 13 & 0,1 & 1,0 & 1,0 & 1,8 & $3,9 \pm 1,01$ & 141 & 0 & 0,1 & 0,9 & 2,3 & $3,3 \pm 0,14$ \\
\hline \multirow[t]{2}{*}{ Mai } & 0 & 0 & 0 & 0 & 0 & 0 & 69 & 0,2 & 0,9 & 0,9 & 2,4 & $4,4 \pm 0,22$ \\
\hline & --- & --- & - & ---- r y n & ------ & -------------- & $000--$ & - & - & - & -- & -------- \\
\hline Jan & 62 & 0,2 & 0,6 & 0,5 & 2,9 & $4,2 \pm 0,07$ & 54 & 0,5 & 0,3 & 0,6 & 3,2 & $4,6 \pm 0,70$ \\
\hline Fev & 44 & 0,1 & 0,3 & 0,7 & 2,3 & $3,4 \pm 0,33$ & 71 & 0,1 & 0,2 & 1,0 & 2,7 & $4,0 \pm 0,51$ \\
\hline Mar & 30 & 0 & 0,1 & 0,8 & 2,1 & $3,0 \pm 0,56$ & 92 & 0 & 0 & 0,4 & 2,4 & $2,8 \pm 0,16$ \\
\hline $\mathrm{Abr}$ & 16 & 0 & 0,3 & 0,2 & 1,9 & $2,4 \pm 0,29$ & 102 & 0 & 0 & 0,3 & 2,3 & $2,6 \pm 0,07$ \\
\hline
\end{tabular}

${ }^{1}$ larvas pequenas $(<1,1 \mathrm{~cm}) ;{ }^{2}$ larvas médias (entre $\left.1,1 \mathrm{e} 1,4 \mathrm{~cm}\right) ;{ }^{3}$ larvas grandes $(>1,4 \mathrm{~cm}$ ).

${ }^{4}$ número de orifícios de saída das larvas. Um orifício significa uma broca que saiu do fruto.

${ }^{5}$ Estimativa do número total de larvas (as larvas presentes mais as que já abandonaram o fruto) \pm erro padrão da média. 
mais rápido possível, de preferência diariamente, para destruir os frutos atacados e quebrar o ciclo biológico da praga, visto que em um único fruto infestado podem ocorrer até 33 larvas (Garcia et al., 1997).

De 538 larvas de último ínstar obtidas em 1999, emergiram apenas 14 parasitóides $(2,6 \%$ de parasitismo). Estes são himenópteros pertencentes à família Braconidae. No ano de 2000, nenhum parasitóide foi obtido, das 257 larvas observadas. Aguilar (1999) também cita o baixo índice de parasitismo de larvas de Conotrachelus spp. provenientes do campo e relata, em seus experimentos, a emergência de 20 adultos de microhimenópteros da família Braconidae e cinco moscas da família Tachinidae.

\section{AGRADECIMENTOS}

Ao Dr. Sérgio Antonio Vanin, pesquisador do Museu de Zoologia da Universidade de São Paulo (USP), pela identificação da espécie $C$. humeropictus.

À Associação dos Pequenos Agrossilvicultores do Projeto Reca, pelas facilidades concedidas, nas pessoas dos produtores Sérgio Roberto Lopes e Orestes Copetti.

\section{REFERÊNCIAS BIBLIOGRÁFICAS}

AGUILAR, J.A.D. Aspectos da biologia e do comportamento da broca-dofruto do cupuaçuzeiro: infestação e dano econômico em Manaus. Revista de Agricultura, v.74, p.305-316, 1999.

ALMEIDA, C.M.V.C. de; ALMEIDA, C.F.G. Coleta de cacau silvestre no Estado de Rondônia. Revista Theobroma, v.17, p.65-92, 1987.

BONDAR, G. Curculionídeos do gênero Conotrachelus nocivos ao cacaueiro. Rodriguésia, v.2, p.41-43, 1937.

GARCIA, M.V.B; PAMPLONA, A.M.S.R.; MORAES, L.A.C. Pragas do cupuaçuzeiro: I - A broca-do-fruto. Manaus: EMBRAPA, Amazônia Ocidental, 1997.

LAKER, H.A.; TREVISAN, O. The increasing importance of cupuassu (Theobroma grandiflorum (Schum) in the Amazon Region of Brasil. Cocoa Growers'Bulletin, p.45-52, 1992.

MENDES, A.C. de B.; GARCIA, J. de J. da S.; TREVISAN, O. Ocorrência de coleobrocas nos frutos do cacaueiro em Rondônia. Informe Fitossanitário, v.2, p.1-3, 1982.

MENDES, A.C. de B.; MAGALHÃES, B.P.; OHASHI, O.S. Biologia de Conotrachelus humeropictus, Fiedler, 1940 (Coleoptera: Curculionidae), praga do cacaueiro e do cupuaçuzeiro na Amazônia Brasileira. Acta Amazônica, v.27, p.135-144, 1997.
MENDES, A.C. de B.; TREVISAN, O. Flutuação populacional de Conotrachelus humeropictus Fiedler, 1940 (Coleoptera: Curculionidae), broca dos frutos do cacaueiro Theobroma cacao L. In: COMISSÃO EXECUTIVA DO PLANO DA LAVOURA CACAUEIRA. Informe de Pesquisas 1989/1990. Belém: CEPLAC, 1991. p.27-29.

OLIVEIRA, C.H. A experiência do projeto RECA no plantio de cupuaçuzeiro, no beneficiamento e na comercialização dos frutos. In: SEMINARIO INTERNACIONAL DE PIMENTA-DO-REINO E CUPUAÇU, 1., Belém, 1996. Anais. Belém: EMBRAPA, Amazônia Oriental/JICA, 1997. p.199206. (Documentos, 89).

PAMPLONA, A.M.; SOUZA, A. das G.C.; NUNES, C.D.; GUIMARÃES, R.R.; MORAES, L.A.C. Levantamento da entomofauna do cupuaçuzeiro Theobroma grandiflorum Schum em áreas experimentais da EMBRAPA-CPAA e de produtores. Manaus: EMBRAPA, CPAA, 1992. 4p. (Circular Técnica, 15).

RIBEIRO, G.D. 1997. Situação atual e perspectivas da cultura do cupuaçuzeiro (Theobroma grandiflorum, Schum) no Estado de Rondônia, Brasil. In: SEMINÁRIO INTERNACIONAL DE PIMENTA-DO-REINO E CUPUAÇU, 1., Belém, 1996. Anais. Belém: EMBRAPA, Amazônia Oriental/JICA, 1997. p.109-118. (Documentos, 89).

SILVA, A. de B.; SOUZA, L. A. de; SILVA, A. T. de A. Pragas do cupuaçuzeiro e seus inimigos naturais. In: SEMINÁRIO INTERNACIONAL DE PIMENTADO-REINO E CUPUAÇU, 1., Belém, 1996. Anais. Belém: EMBRAPA, Amazônia Oriental/JICA, 1997. p.151-159. (Documentos, 89).

SILVA, A.G.A.; GONÇALVES, C.R.; GALVÃO, D.M.; GONÇALVES, A.J.L.; GOMES, J.; SILVA, M.N.; SIMONI, L. 1968. Quarto catálogo dos insetos que vivem nas plantas do Brasil, seus parasitos e predadores; insetos hospedeiros e inimigos naturais. t.1, parte 2. Rio de Janeiro: Ministério da Agricultura, Laboratório Central de Patologia Vegetal, 1968. 622p.

TEIXEIRA, C.A.D.; VELD, P. van der. As pequenas brocas do cupuaçu, Xyleborus sp. e Hypocryphalus sp. (Coleoptera: Scolytidae): danos e indicações de manejo em sistemas agroflorestais de Rondônia. Porto Velho: EMBRAPA, CPAF, 1997. 13p. (Circular Técnica, 27).

THOMAZINI, M.J. Medidas para o controle da broca-dos-frutos do cupuaçuzeiro. Rio Branco: EMBRAPA,CPAF/AC, 1998. 2p. (Instruções Técnicas, 11).

TREVISAN, O. Comportamento da broca dos frutos do cacau Conotrachelus humeropictus Fiedler, 1940 (Col.: Curculionidae), em Rondônia. Piracicaba, 1989. 57p. Dissertação (Mestrado) - Escola Superior de Agricultura "Luiz de Queiroz", Universidade de São Paulo.

TREVISAN, O.; MENDES, A.C. de B. Ocorrência de Conotrachelus humeropictus Fiedler, 1940 (Coleoptera: Curculionidae) em frutos de cupuaçu Theobroma grandiflorum (Willd. EX Spreng. Schum.) (Sterculiaceae). In: CONGRESSO BRASILEIRO DE ENTOMOLOGIA, 13., Recife, 1991. Resumos. Recife: Sociedade Entomológica do Brasil, 1991. p.137.

VENTURIERI, G.A. Cupuaçu: a espécie, sua cultura, usos e processamento. Belém: Clube do Cupu, 1993. 108p.

VENTURIERI, G.C.; MAUÉS, M.M.; MIYANAGA, R. Polinização do cupuaçuzeiro (Theobroma grandiflorum, Sterculiaceae): Um caso de cantarofilia em uma fruteira Amazônica. In: SEMINÁRIO INTERNACIONAL DE PIMENTA-DO-REINO E CUPUAÇU, 1., Belém, 1996. Anais. Belém: EMBRAPA, Amazônia Oriental/JICA, 1997. p.341-350. (Documentos, 89).

$\overline{\text { Recebido em } 08.02 .01}$ 